\title{
Hardiness, Sensation Seeking, Optimism and Social Support as Predictors of Stress Tolerance among Private Secondary Schools Teachers in Lagos State
}

\section{Segun-Martins Ibironke Opeyemi ${ }^{*}$}

Department of Pure and Applied Psychology, Adekunle Ajasin University, Akungba-Akoko, Ondo State, Nigeria

"Corresponding author: Segun-Martins Ibironke Opeyemi, Department of Pure and Applied Psychology, Adekunle Ajasin University, Akungba-Akoko, Ondo State, Nigeria, E-mail: monique.seguin@uqo.ca

Received date: December 01, 2015; Accepted date: August 30, 2016; Published date: September 06, 2016

Copyright: (c) 2016 Opeyemi SMI. This is an open-access article distributed under the terms of the Creative Commons Attribution License, which permits unrestricted use, distribution, and reproduction in any medium, provided the original author and source are credited.

\begin{abstract}
This study investigated the extent to which hardiness, sensation seeking, optimism and social support predicts stress tolerance among private secondary school teachers in Lagos State, Nigeria. Using an ex post-facto design, 272 teachers (123 males; 149 females) were selected from 8 privates secondary schools in Lagos State. Their ages ranged from 21 to 58 years with a mean age of 37.57 years $(S D=11.29)$. The study instruments contain short hardiness scale, sensation seeking scale, optimism scale, social support scale and stress tolerance scale. Six hypotheses were generated and tested using Pearson Product Moment Correlation and Hierarchical Multiple Regression Analysis. The result showed that hardiness significantly predicted stress tolerance among private secondary school teachers $(\beta=-0.24 ; t=-5.90 ; p<0.01)$. Sensation seeking significantly predicted stress tolerance among private secondary school teachers $(\beta=0.18 ; t=3.88 ; p<0.01)$. Also, optimism significantly predicted stress tolerance among private secondary school teachers $(\beta=-0.18 ; t=-3.72 ; p<0.01)$. Similarly social support had a positive relationship with stress tolerance among private secondary school teachers $(r=(270)=.562 ; p<0.01)$. However, educational qualification significantly predicted stress tolerance among private secondary school teachers $(\beta=0.27 ; t=-3.85 ; p<0.01)$. Finally, the multiple regression analysis also indicated that hardiness, sensation seeking, optimism, and social support jointly predicts stress tolerance among private secondary school teachers $[F(1,268)=27.25 ; p<0.01]$. Thus, it is recommended that management should employ more qualified teachers and provide conductive work environment for their employees.
\end{abstract}

Keywords: Hardiness; Sensation seeking; Optimism; Social support; Stress tolerance

\section{Introduction}

\section{Background to the Study}

Psychological studies that have investigated the stress tolerance among academicians, especially following the ever-increasing demands of change associated with developments in technology, and curriculum [1]. Human stress is not a new concept they have been a subject of investigation for a long time now. However, these investigations have seldom been centred among individuals in the teaching profession [1].

Stress is an adaptive response to a situation that is perceived as challenging or threatening to the person's well-being [2]. Stress is the person's reaction to a situation, not the situation itself. Moreover, we experience stress when we believe that something will interfere with our need Fulfilment [1]. Stress is generally defined as the body's nonspecific response or reaction to demands made on it, or to disturbing events in the environment. It is a process by which we perceive and cope with environmental threats and challenges [3]. Personal and environmental events that cause stress are known as stressors [2]. Therefore, stress is simply defined as emotional disturbances or changes caused by stressors. Workplace stress has been shown to have a detrimental effect on the health and well-being of academic employees [1], as well as a negative impact on workplace productivity and profits [4].
However, while compared to others, teaching has been identified as one of the most stressful occupation in many countries [4]. An intriguing problem facing stress researchers has been the individual variability of stress reaction. Teachers respond differently to stress, and also not all teachers are equally vulnerable to its effect. It is also opined that the experience of stress is a very personal matter Goldberger and Breznitz [5], and each person must have developed his or her own coping styles for getting through life successfully and it is the breakdown of these coping patterns that cause stress in a person. Even when exposed to a minor stressful situation, certain people experience high level of stress and become ill, while others experience much less stress and remain calm and composed [1].

Teaching related stress, commonly termed 'teacher stress', is defined as a teacher's experience of "unpleasant, negative emotions, such as anger, anxiety, tension, frustration, or depression, resulting from some aspect of their work as a teacher" [6]. Sources of teacher stress are varied [7]. Some of the more common sources include the need to make adaptations to sudden curriculum changes and feeling of disempowerment [8-10]. Apart from school curriculum changes, a change in school structure may also be a source of stressor. Such change causes erosion of collegial relationship and fosters feeling of inequity and uncertainty [11].

The term 'Stress Tolerance' refers to a person's ability to withstand stress without becoming seriously impaired [1]. Stress tolerance is a term related to effective coping and coping strategies. It is the ability of a person to handle emotionally charged situations and to tolerate stress, in demanding environments. Stress tolerance is defined as the 
ability to endure stress, strain and pain without serious harm [1] Pestonjee [12] and Franken et al. [13] are of the opinion that work related stress is inevitable and workers vary in their ability to tolerate well with stress.

Hardiness is a personal characteristic adjusting the way to tolerate with the stressful situations [14]. The construct of hardiness was first introduced by Kobasa [15], who defined it as a resistance resource in the encounter with stressful situations. It is considered as a pattern of personality characteristics comprising three mutually related dispositions - commitment, control, and challenge [15,16]. Hardy teachers tend to appraise potentially stressful events as less threatening and less undesirable than others do Rhodewalt and Zone [17], Wiebe [18] and Sezgin [19] and have more responsible work behaviours and are more efficient in stressful tasks Manning et al. [20] which in turn may help in their ability to tolerate stressful events, situation, and tasks.

Sensation seeking is another personality trait that helps individuals manages stress [21]. It was first described by Zuckerman [22], sensation seeking is a generalized preference for high or low levels of sensory stimulation. Sensation seeking is a personality trait defined by the search for experiences and feelings that are "varied, novel, complex and intense" and by the readiness to take physical, social, legal, and financial risks for the sake of such experiences [13,22].

Sensation seeking is a dimension of personality that has been defined by the need for varied, novel, complex, and intense sensory stimulation and the level of risk taken in an effort to satisfy the desire for such stimulation. High Sensation Seeking has been associated with participation in a variety of intense, antigenic stimulus events such as viewing horror movies [22].

Optimism is another variable that predict stress tolerance level among private school teachers. Optimism reflects an individual's expectation of a positive outcome in most situations. It has been argued that optimism enables the individual to set goals, make commitments, tolerate with adversity and pain and recover from trauma and stress [23]. In comparison, pessimists are more likely to deal with stress by giving up or by engaging in denial $[23,24]$.

Social Support is a broad concept that has been studied across disciplines evolving from psychology, sociology and medicine [25]. It is define as the perception and actuality that one is cared for, has assistance available from other people, and that one is part of a supportive social network. These supportive resources can be emotional (e.g., nurturance), tangible (e.g., financial assistance), informational (e.g., advice), or companionship (e.g., sense of belonging) and intangible (e.g. personal advice) [26].

\section{Purpose of the Study}

The purpose of this research is to establish prediction between hardiness, sensation seeking, optimism and social support and how these variables will interact to predict stress tolerance among the private school teachers.

\section{Review of Related Studies on Stress and Stress Tolerance}

Several studies Kahill [27] and Lee et al. [28] found that perceived occupational stress has been associated with high psychological demand that often induce stress. Stilwell et al. [29] submitted that teachers who remain in teaching job with inadequate numbers of teachers would experience added stress and greater workload.

Hari and Soumya [30], Biju and Sananda [31] that have examined the relationship between teacher's occupational stress and their qualification have shown that postgraduate teachers have significantly less job satisfaction on job role item than the undergraduate and graduate teachers [32]. Hong Kong teachers without finishing professional training and of junior rank reported themselves to be more burned out in a study by [33]. Quite opposite to this, teacher's qualification was not correlated to their stress level [34]. Other data support no significant difference between stress and academic qualifications of the teachers [35].

\section{Hardiness and Stress Tolerance}

Despite a common acknowledgement that personality factors play a critical role mediating stress, these factors have been overlooked in majority of empirical studies on stress [35]. A notable exception has been a series of studies carried out by $[15,36]$. Kobasa et al. [36] explored the concept of "personality hardiness" as a resistance resource that mediates the negative consequences of high level stress. Hardiness reflects the individual's response to life events both personally and professionally $[15,37]$.

\section{Sensation Seeking and Stress Tolerance}

Zuckerman et al. [38] cited that individuals high in sensationseeking have a tendency to involve in variety of works that is seen as stressful. In other words, high sensation-seekers are less likely to label risky behaviours as risky as and more likely to either try or repeat a variety of risky activities than their peers that are low in sensationseeking [39]. Studies have found that sensation-seeking is higher in private schools than in public school [40]. This may explain part of the developmental basis of sensation-seeking and reckless/risky behaviour $[41,42]$.

\section{Dispositional Optimism and Stress Tolerance}

The dispositional optimism literature pioneered by Scheier et al. [43], views optimism as generalized positive expectations about future events. Research suggests that optimists cope with stress in more adaptive ways than pessimists [24]. Optimists are more likely to engage in action-oriented, problem-focused coping, are more willing than pessimists to seek social support, and are more likely to emphasize the positive in their appraisals of stressful events. In comparison, pessimists are more likely to deal with stress by giving up or by engaging in denial. In a related line of research, Christopher Peterson and Martin Seligman have studied how people explain bad events (personal setbacks, mishaps, disappointments, and such). They identified a pessimistic explanatory style in which some people tend to blame setbacks on their personal shortcomings [44].

\section{Social Support and Stress Tolerance}

McCauley [45] indicated that the social relation integral to an exercise environment are significant determinants of subjective wellbeing, including ability to tolerate stress among teachers. McCulloch [46] found that social support was a significant predictor of mental health outcome. A low level of social support causes stress and worsening of physical functioning. McCauley et al. [45] also suggested that psychological functioning were associated with a higher level of 
social support. Supportive relationships within social networks are essential for enhancing stress tolerance and ensuring happiness in later life [47].

Caplan and Killelea [48] consider social support to be significant when dealing with a stressful situation. Also, a great deal of research reports it as an important source of emotional support that facilitates the psychological adjustment to stress. Perceive social support act as a barrier against high-stress for individuals, satisfy their feelings of commitment and help protect and strengthen feelings of identity. Having a low level of social support can negatively affect individuals' mental status [49]. Social support has shown to exert positive influence on dealing with stress Holahan et al. [50], help tolerate stress Ford et al. [51], Gentry and Kobasa [52], Kobasa [36], and received social support, such as the frequency of helpful interactions [24].

\section{Research Hypotheses}

1. There will be a significant positive relationship between social support and stress tolerance among private secondary school teachers.

2. Educational status will significantly predict stress tolerance among private secondary school teachers.

3. Hardiness will significantly predict stress tolerance among private secondary school teachers.

4. Sensation seeking will significantly predict stress tolerance among private secondary school teachers.

5. Optimism will significantly predict stress tolerance among private secondary school teachers.

6. Hardiness, sensation seeking, optimism, and social support will have a significant joint prediction on stress tolerance among private secondary school teachers.

\section{Methods}

\section{Research design}

This study adopted ex post-facto design. The independent variables are hardiness, Sensation seeking, optimism, and social support while the dependent variable is stress tolerance.

\section{Study setting}

The study was conducted among teachers who were selected as participants from eight (8) private secondary schools in Lagos State. A total number of 350 questionnaires were administered but the researcher found only 272 copies analysable.

\section{Sampling technique}

The researcher employed an accidental sampling technique because only those available at the time of the distribution of the questionnaire were used.

\section{Participants}

Data were collected from 272 participants comprising 123 males (45.2\%), 149 females (54.8\%), whose age ranged from 21 and 58 with a mean age of (37.57) and the standard deviation of (11.29). The demographic variable is represented as thus. In term of Marital status 133 were single $(48.9 \%), 121$ were married $(44.5 \%), 11$ were divorce (4.0\%), 7 were widowed (2.6\%). In term of educational status 108 were
$\mathrm{OHD} / \mathrm{NCE}$ (39.7\%), 130 were $\mathrm{HND} / \mathrm{BSC}$ (47.8\%), 34 were postgraduate $(12.5 \%)$. In term of length of service 51 were 0 -1years (18.8\%), 78 were $2-5$ years $(28.7 \%), 40$ were $6-10$ years $(14.7 \%), 103$ were 11 years \& above (37.9\%).

\section{Instruments}

In this study, a questionnaire was designed to collect data from participant. There were six sections in the questionnaires, which included the measurement of hardiness, sensation seeking, optimism, social support, stress tolerance and the demographic variables.

Section A: This comprise of the demographic variables such as age, gender, marital status, educational status and length of service.

\section{Section B: Hardiness Scale}

Personality hardiness was measured using short hardiness scale developed by Paul (1995). A 12 -item Liker type scale sample items include; "Trying my best at work makes a difference", "I know why I am doing what I am doing at work". Paul (1995) obtained a Cronbach's alpha coefficient for the total hardiness measure is .83 . The present study had a Cronbach's alpha of 62 .

\section{Section C: Sensation Seeking Scale}

The Sensation Seeking was measured using the Arnett Inventory of Sensation Seeking (AISS), developed by [40]. This had a 20 items with two subscales of 10 items each, Intensity and Novelty. Sample items include; "In general, I work better when I'm under pressure". The present study had the reliability of 66 .

\section{Section D: Social Support Scale}

The multidimensional scale of perceived social support developed by Zimet et al. [53] was used to measure social support. The scale was design to reflect the perceived social support among the teachers. The scale had 12 items and was measure using a seven point Likert scale. Sample items include: "There is a special person who is around when I am in need. Zimetet al. [53] obtained a Cronbach's coefficient alpha of .84 to .92 based on the sample of the study. The present study had a Cronbach's alpha of 77.

\section{Section E: Optimism Scale}

The Life Orientation Test-Revised (LOT-R) developed by Scheier et al. [43] was used to measure optimism. The scale is a 10 items, rated on a five point Likert scale. Sample items include; "I'm always optimistic about my future"; "Overall, I expect more good things to happen to me than bad". Scheier et al. [43] obtained a Cronbach's coefficient alpha of 77. The present study obtained a Cronbach's alpha of 48 .

\section{Section F: Stress Tolerance Scale}

The Stress Tolerance Questionnaire developed by First Generation @ Mohawk College (2011-12) was used to measure teachers stress tolerance level. While the overall study reliability tests produce a Cronbach's alpha of 85 .

\section{Data Analysis}

The researcher used Pearson Product Moment Correlation (PPMC) to test hypothesis 1 in order to determine the direction of relationship among the study variables. Hypotheses 2 to 6 was analyse using Hierarchical multiple regression analysis in order to know the independent and joint prediction of hardiness, sensation seeking, optimism and social support on stress tolerance. 
Citation: Opeyemi SMI (2016) Hardiness, Sensation Seeking, Optimism and Social Support as Predictors of Stress Tolerance among Private Secondary Schools Teachers in Lagos State. Clin Depress 2: 116.

Page 4 of 7

\section{Results}

\section{Test of relationship among variables and test of hypothesis 1}

The first analysis involved inter-correlations of all the variables of the study (Table 1).

\begin{tabular}{|c|c|c|c|c|c|c|c|c|c|c|}
\hline Variable & 1 & 2 & 3 & 4 & 5 & 6 & 7 & 8 & 9 & 10 \\
\hline 1. Age & 1 & & & & & & & & & \\
\hline 2. Gender & -.03 & 1 & & & & & & & & \\
\hline 3. Marital Status & $.66^{* *}$ & -.11 & 1 & & & & & & & \\
\hline 4. Education Qualification & $.30^{* *}$ & -.08 & $.47^{* *}$ & 1 & & & & & & \\
\hline 5. Length of Service & $.78^{* *}$ & .08 & $.62^{* *}$ & .11 & 1 & & & & & \\
\hline 6. Hardiness & -.05 & $-.19^{* *}$ & -.07 & -.01 & -.10 & 1 & & & & \\
\hline 7. Social Support & .09 & $-.14^{*}$ & $.14^{*}$ & -.11 & .11 & $.31^{\star *}$ & 1 & & & \\
\hline 8. Optimism & .04 & .08 & .10 & -.02 & $.13^{*}$ & $-.28^{* *}$ & $-.32^{\star *}$ & 1 & & \\
\hline 9. Sensation Seeking & .02 & $-.15^{\star}$ & .06 & .02 & .01 & $.12^{*}$ & -.05 & -.02 & 1 & \\
\hline 10. Stress Tolerance & .11 & .09 & -.03 & $-.23^{* *}$ & $.12^{*}$ & -.01 & $.56^{\star *}$ & $-.31^{* *}$ & .09 & 1 \\
\hline Mean & 37.57 & - & - & - & 2.72 & 21.20 & 64.03 & 21.57 & 44.70 & 52.32 \\
\hline Std. D. & 11.29 & - & - & - & 1.16 & 4.68 & 9.22 & 5.42 & 5.04 & 11.71 \\
\hline
\end{tabular}

Table 1: Correlation matrix showing the mean, sd and inter variable relationships among variables of the study.

The result in Table 1 showed that Education Qualification had a significant negative relationship with Stress Tolerance ( $\mathrm{r}(270)=-.23$; $\mathrm{p}<0.01$ ), Length of Service had a significant positive relationship with Stress Tolerance $(\mathrm{r}(270)=.12 ; \mathrm{p}<0.05)$, Optimism had a significant negative relationship with Stress Tolerance $(\mathrm{r}(270)=-.31 ; \mathrm{p}<0.01)$.

\section{Test of Hypotheses}

\section{Hypothesis 1}

Results in Table 1 above showed that social support had a positive relationship with stress tolerance among private secondary school

\begin{tabular}{|c|c|c|c|c|c|c|c|}
\hline Predictor variables & $\mathbf{R}$ & $\mathbf{R}^{2}$ & $\Delta \mathbf{R}$ & $\mathbf{F}$ & B & $\mathbf{t}$ & $\mathbf{P}$ \\
\hline Step 1 & 0.31 & 0.10 & 0.09 & 5.57 & - & - & - \\
\hline Age & & & & & 0.22 & $2.14^{*}$ & $<0.05$ \\
\hline Gender & & & & & 0.65 & 1.08 & $>0.05$ \\
\hline Marital Status & & & & & -0.52 & -0.58 & $>0.05$ \\
\hline Education Qualification & & & & & 0.27 & $-3.85^{\star \star}$ & $<0.01$ \\
\hline Length of Service & & & & & 0.01 & 0.10 & $>0.05$ \\
\hline Step 2 & 0.70 & 0.48 & 0.46 & 27.25 & - & - & - \\
\hline Hardiness & & & & & -0.24 & $-5.90^{\star *}$ & $<0.01$ \\
\hline Social Support & & & & & 0.60 & $11.57^{* *}$ & $<0.01$ \\
\hline
\end{tabular}

teachers $(\mathrm{r}=(270)=.56 ; \mathrm{p}<0.01)$. Therefore, hypotheses 1 which state that social support will have a significant positive relationship with stress tolerance among private secondary school teachers was confirmed and therefore accepted.

In order to test hypotheses 2, 3, 4, 5 and 6 hierarchical multiple regression analysis was conducted (Table 2). 


\begin{tabular}{|l|l|l|l|l|l|l|l|}
\hline Optimism & & & & & -0.18 & $-3.72^{\star \star}$ & $<0.01$ \\
\hline Sensation Seeking & & & & & 0.18 & $3.88^{\star \star}$ & $<0.01$ \\
\hline
\end{tabular}

Table 2: Summary of hierarchical multiple regression analysis showing the joint and independent contributions of the demographic variable, hardiness, social support, optimism and sensation seeking on stress tolerance.

Result in Table 2 above showed in step 1 , that gender $(\beta=0.65$; $\mathrm{t}=1.08 ; \mathrm{p}>0.05)$, marital status $(\beta=-0.52 ; \mathrm{t}=-0.58 ; \mathrm{p}>0.05)$, and length of service $(\beta=0.01 ; \mathrm{t}=0.10 ; \mathrm{p}>0.05)$ had no significant prediction on stress tolerance. Furthermore, age significantly predict stress tolerance $(\beta=0.22 ; \mathrm{t}=2.14 ; \mathrm{p}<0.05)$.

\section{Test of hypothesis 2}

Results in Table 2 above showed in step 1, that educational status significantly predicted stress tolerance among private secondary school teachers $(\beta=0.27 ; \mathrm{t}=-3.85 ; \mathrm{p}<0.01)$. Therefore, hypotheses 2 which state that educational status will significantly predict stress tolerance among private secondary school teachers was confirmed and therefore accepted.

\section{Test of hypothesis 3}

Results in Table 2 above showed in step 2, that hardiness significantly negatively predicted stress tolerance among private secondary school teachers $(\beta=-0.24 ; \mathrm{t}=-5.90 ; \mathrm{p}<0.01)$. Therefore, hypotheses 3 which state that hardiness will significantly predict stress tolerance among private secondary school teachers was confirmed and therefore accepted.

\section{Test of hypothesis 4}

Results in Table 2 above showed in step 2, that sensation seeking significantly predicted stress tolerance among private secondary school teachers $(\beta=0.18 ; \mathrm{t}=3.88 ; \mathrm{p}<0.01)$. Therefore, hypotheses 4 which stated that sensation seeking will significantly predict stress tolerance among private secondary school teachers was confirmed and therefore accepted.

\section{Test of hypothesis 5}

Results in Table 2 above showed in step 2, that optimism significantly predicted stress tolerance among private secondary school teachers $(\beta=-0.18 ; \mathrm{t}=-3.72 ; \mathrm{p}<0.01)$. Therefore, hypotheses 5 which stated that optimism will significantly predict stress tolerance among private secondary school teachers was confirmed and therefore accepted.

\section{Test of hypothesis 6}

Results in Table 2 above showed in step 2, on the joint contribution of all the independent variables to the prediction of stress tolerance among private secondary school teachers, the results indicated that all the independent variables when pulled together yield a multiple $\mathrm{R}$ of 0.70 and $\mathrm{R}^{2}$ of $0.48(\mathrm{~F}(1,268)=27.25 ; \mathrm{p}<0.01)$. This indicates that all the independent variables contributed $48 \%$ of the variance in stress tolerance. Meanwhile, other variables not considered in this study therefore accounts for $52 \%$. Therefore hypothesis 6 which stated that hardiness, sensation seeking, optimism, and social support will have a significant joint prediction on stress tolerance among private secondary school teachers was confirmed and therefore accepted.

\section{Discussion}

This study investigated the extent to which hardiness, sensation seeking, optimism and social support predict stress tolerance among private secondary school teachers in Lagos State, Nigeria.

Hypothesis 1 which stated that social support will have a significant positive relationship with stress tolerance among private secondary school teachers was confirmed by the result in Table 1. This implies that those who reported high on social support show a high tendency towards stress tolerance and vice-versa. Also, teachers who received support from family, friends and co-workers tolerate stress more than the teacher who does not receive such help. This result was confirmed by the study of Caplan and Killelea [48] who consider social support to be significant when dealing with a stressful situation. Social support has shown to exert positive influence on dealing with stress [50].

Hypothesis 2 which stated that educational status will significantly predict stress tolerance among private secondary school teachers was confirmed by the result in Table 2 , step 2 . The result indicated that educational status significantly predicts stress tolerance. This implies that the higher the level of education the lower the level of stress tolerance and vice-versa. This is similar to the study of Mariya and Tahira [54] who examined the relationships of a set of independent variables (gender, qualification, teaching experience, salary, subjects taught and marital status) with occupational stress among secondary school teachers. According to the results of the analysis, nearly half of the secondary school teachers experience less stress towards their job and males display more occupational stress towards job than the females. Moreover, the trained graduate teachers are found to have higher occupational stress than post-graduate and untrained teachers.

Hypothesis 3 which stated that hardiness will significantly predict stress tolerance among private secondary school teachers was confirmed by the result in Table 2, step 2 . The result indicated that hardiness significantly predicts stress tolerance. This implies that adjusting the way teachers tolerate with the stressful situations help them to convert stressful situations into opportunities for improving the performance, leadership, mental growth, and service in the teaching profession. This result is in line with the findings of Chan (2003) who assessed hardiness and stress among teachers and found that hardiness had significant impact on teachers' ability to tolerate stress. Gentry and Kobasa [52] and Kobasa [36] found out that hardiness has also been shown to be associated with the individual's use of active, problem-focused coping strategies for dealing with stressful events.

Hypothesis 4 which stated that sensation seeking will significantly predict stress tolerance among private secondary school teachers was confirmed by the result in Table 2, step 2 . The result indicated that sensation seeking significantly predicts stress tolerance. This implies that the way teachers search for experiences and feelings that are 
varied, novel, complex and intense and by the readiness to take physical, social, legal, and financial risks for the sake of such experiences help them in tolerating stress. This was confirmed by the study of Horvath and Zuckerman [55] who found out in their study using 447 undergraduate students and the results of the multiple regression analysis of the data showed that sensation-seeking was a strong predictor of stress tolerance.

Hypothesis 5 which stated that optimism will significantly predict stress tolerance among private secondary school teachers was confirmed by the result in Table 2, step 2. The result indicated that optimism significantly predicts stress tolerance. This implies that teachers who are optimistic are able to tolerate stress than the pessimistic teachers. These findings supported past studies, for instance, Aspinwall and Taylor [24] who found out that optimist cope with stress in more adaptive ways than pessimists. Also this finding is similar to the work of Scheier et al. [43] who found a correlation between optimism and relatively good physical health in a sample of college students.

Hypothesis 6 which stated that hardiness, sensation seeking, optimism, and social support will significantly, jointly predict stress tolerance among private secondary school teachers was confirmed by the result in Table 2. This implies that teachers who are high in hardiness, sensation seeking, optimism, and social support have high tolerance for stressors on their job.

\section{Conclusion}

To this end, this study shows that hardiness, sensation seeking, optimism, and social support jointly predicts stress tolerance among private secondary school teachers. The contribution of conducting such research is to enable principals, management, and other people to make their effort in improving hardiness, sensation seeking, optimism and social support as a contributing factors to stress tolerance. Researching on these variables would allow educationist, professionals, parents, government and psychologist to design psychological intervention or programs that can enhance and encourage stress tolerance. Also management should provide support for the teachers.

\section{Implication and Recommendation}

A number of implications have emerged from the results of the present study. First, when a stressful situation arises in the workplace, preventive strategies can be infused by enhancing employees' internal resources [56-61]. Management should provide a conductive work environment for their employees as this will enable them to work efficiently and effectively. Employing more qualified teachers is a potential remedy for reducing workload, as this will lead to division of labour and reduces the number of courses taken by each teacher. Also, management should not set unrealistic goals for their employees. They should know their employees' limitation and the employees should not always aim for perfection.

\section{Limitation}

This study like other studies has some limitations. Firstly, only 272 respondents were involved in the study. This sample size was too small for generalization, which could merely provide illustrative and tentative results. Another important limitation in this study is that investigation of stress tolerance is limited to private secondary school teachers alone. This did not allow for a comparison to be made across occupations.

\section{References}

1. Chan DW (2002) Stress, Self-Efficacy, Social Support, and Psychological Distress Among Prospective Chinese Teachers in Hong Kong. Educational Psychology 22: 557 - 569.

2. Afolabi AO, Imhonde HO (2002) Situational factors in work behavior and incidence of stress. Nigerian Journal of Applied Psychology 7: 126-137.

3. Myers DG (2005) Stress and Health, in: Exploring Psychology. 6th ed. New York, Worth Publishers.

4. Cooler CL, Sloan S, Williams S (1988) Occupational Stress Indicator. Slough UK: NFER-Nelson.

5. Goldberger L, Breznitz C (1986) Hand Book of Stress: Theoretical and Clinical Aspects, New York: The McMilan Inc.

6. Kyriacou C (2001) Teacher stress: Directions for suture research. Educational Review 53: 27-35.

7. Dewe PJ (1986) An investigation into the causes and consequences of teacher stress. New Zealand Journal of Educational Studies 21: 145-157.

8. Brown M, Ralph S, Brember I (2002) Changed-linked work-related stress in British teachers. Research in Education 67: 1-12.

9. Moriarty V, Edmonds S, Blatchford P, Martin C (2001) Teaching young children: perceived satisfaction and stress. Educational Research 43: 33-46.

10. Selye H (1999) The Stress of Life (Revised Science, Excel Books Edition), New York, Tata McGraw Hill.

11. Gordon DG (2002) Discipline in the music classroom: One component contributing to teacher stress. Music Education Research 4: 157-165.

12. Pestonjee DM (1999) Stress and Coping, the Indian Experience, Sage Publication.

13. Franken RE, Gibson KJ, Rowland GL (1992) Sensation seeking and the tendency to view the world as threatening. Personality and Individual Differences 13: 31-38.

14. Azeem SM (2010) Personality hardiness, job involvement and job burnout among teachers. International journal of vocational and technical education 2: 36-40.

15. Kobasa SC (1979) Stressful life events, personality, and health: An inquiry into hardiness. Journal of Personality and Social Psychology 37: 1-11.

16. Maddi SR (1999) Comments on trends in hardiness research and theorizing. Consulting Psychology Journal Practice and Research 51: 67-71.

17. Rhodewalt F, Zone JB (1989) Appraisal of life change, depression, and illness in hardy and non-hardy women. Journal of Personality and Social Psychology 56: 81-88.

18. Wiebe DJ (1991) Hardiness and stress moderation: A test of proposed mechanisms. Journal of Personality and Social Psychology 60: 89-99.

19. Sezgin F (2009) Relationships between teacher organizational commitment, psychological hardiness and some demographic variables in Turkish primary schools. Journal of Educational Administration 47: 630-651.

20. Manning MR, Williams RF, Wolfe DM (1988) Hardiness and the relationship between stressors and outcomes. Work \& Stress 2: 205-216.

21. Campbell JB, Tyrrell D, Zingaro M (1993) Sensation seeking among whitewater canoe and kayak paddlers. Personality and Individual Differences 14: 489-491.

22. Zuckerman M (1991) Behavioral expressions and biosocial bases of sensation seeking. Cambridge, MA: Cambridge University Press.

23. Schneider MJ, Leitenberg H (1989) A comparison of aggressive and withdrawn children's self-esteem, optimism and pessimism, and causal attribution for success and failure. Journal of Abnormal Child Psychology 17: 133-144.

24. Aspinwall L, Taylor SE (1992) Modeling cognitive adaptation: a longitudinal investigation of the impact of individual differences and 
coping on college adjustment and performance. Journal of Personality and Social Psychology 63: 989-1003.

25. House JS (1981) Work stress and social support. Reading, MA: AddisonWesley. Krause, N (1986) "Social support, stress, well-being". Journal of Gerontology 41: 512-519.

26. Hogan BE, Linden W, Najarian B (2002) Social support interventions; Do they work? Clinical Psychology Review 22: 381-440.

27. Kahill S (1988) Symptoms of professional burnout. A review of the empirical evidence. Canadian Psychology 29: 284-297.

28. Lee SS, Shen HC, Cheng Y, Tsai P, Guo YL (2005) Occupational stress in nurses in psychiatric institutions in Taiwan. Journal of Occupational Health 47: 218-225.

29. Stilwell B, Diallo K, Zurn P, Dal Poz MR (2003) Developing evidencebased ethical policies on the migration of health workers: Conceptual and practical challenges. Human Resources for Health 1:8.

30. Hari SG, Soumya S (2010) Study on Strategic Importance of High Stress Tolerance Limit among Media Personnel. View Point 9-15.

31. Biju AR, Sananda HS (2013) Stress Tolerance, Altruistic Behaviour, and Level of Aspiration Among Adolescent Students". Golden Research Thoughts 3: Department of Psychology, University of Kerala.

32. Mondal J, Shrestha S, Bhaila A (2011) School Teachers: Job stress and Job Satisfaction, Kaski, Nepal. International Journal of Occupational Safety and Health 1: 27-33.

33. Lau P, Yuen M, Chan R (2005) Do demographic characteristics make a difference to burnout among Hong Kong secondary school teachers? Social Indicators Research Series 25: 491-516.

34. Lam Yee ML (2006) Teacher stress encountered by Hong Kong secondary and primary school teachers: Similarity and Disparity. A Dissertation submitted in partial fulfillment of the requirements for the degree of Master of Education in Faculty of Education, the University of Hong Kong.

35. Mokdad M (2005) Occupational stress among Algerian teachers. Afr Newslett on Occup Health and Safety 15: 46-47.

36. Kobasa SC, Maddi SR, Kahn S (1982) Hardiness and health: A prospective study. Journal of Personality and Social Psychology 42: 168-177.

37. Rush MC, Schoel WA, Barnard SM (1995) Psychological resiliency in the public sector: "hardiness" and pressure for change. J Voc Behav 46: 17-39.

38. Zuckerman M, Kuhlman DM, Joireman J, Teta P, Kraft M (2000) A comparison of three structural models for personality: the big three, the big five and the alternative five. Journal of Personality and Social Psychology 65: 757-768

39. Hoyle RH, Stephenson MT, Palmgreen P, Lorch EP, Donohew L (2002) Reliability and validity of a brief measure of Sensation seeking. Personality and Individual Differences 32: 404-414.

40. Arnett JJ (1996) Sensation seeking, aggressiveness, and adolescent reckless behavior. Personality and Individual Differences 20: 693-702.

41. Rolison MR, Scherman A (2002) Factors influencing adolescents decision to engage in risk-taking behavior. Journal of Adolescence 37: 585-596.

42. Greene R (2000) Hassles, Hardiness and absenteeism: Results of a 3 year longitudinal study. Work ad Stress 9: 448- 462.

43. Scheier MF, Carver CS, Bridges MW (1994) Distinguishing optimism from neuroticism (and trait anxiety, self-mastery, and self-esteem): A reevaluation of the Life Orientation Test). Journal of Personality and Social Psychology 67: 1063-1078.
44. Peterson C, Seligman R, Valliant (1988) Optimism and physical wellbeing. In E. C. Chang (Ed), Optimism \& pessimism: Implications for theory, research, and practice 127 145. Washington, DC: American Psychological Association.

45. McCauley E, Blissmer B, Marquez D, Lerome G, Kramer A (2000) Social relations, physical activity and well-being in older adults. Prev Med 33: 608-17.

46. McCulloch BJ (1995) Relationship of family proximity and social support to mental health of older rural adults: The Appalachian Context. Journal of Aging Studies 9: 65-81.

47. Chan YK, Rance PL (2005) Network size, social support and happiness in later life: a comparative study of Beijing and Hong Kong. Journal of Happiness Studies 7: 87-112.

48. Caplan G, Killelea M (1976) Support system and Mutual Help. Gruw \& Stratton. New York.

49. Ozbas AA (2008) Determination of the level of distress and perceived social support of the breast cancer patients, Gazi University Institute of Health Sciences Department of Nursing. Unpublished Master's Thesis, Ankara.

50. Holahan CJ, Moos RH, Holahan CK, Brennan PL (1997). "Social context, coping strategies, and depressive symptoms: An expanded model with cardiac patients". Journal of Personality and Social Psychology 72: 918-928.

51. Ford IW, Gordon S, Eklund RC (2000) Coping with sport injury: Resource loss and the role of social support. Journal of Personality and Interpersonal Loss 4: 243-256.

52. Gentry WD, Kobasa SC (1984) Social and psychological resources mediating stress-illness relationships in humans. In W. D. Gentry (Ed.), Handbook of behavioural medicine, (87-116). New York: Guilford Press.

53. Zimet GD, Dahlem NW, Zimet SG, FarleyGK (1988) The Multidimensional Scale of Perceived Social Support. Journal of Personality Assessment 52: 30-41.

54. Mariya A, Tahira K (2008) Demographic differences and occupational stress of secondary school teachers. European Scientific Journal 8: $159-175$

55. Horvath P, Zuckerman M (1992) Sensation seeking, risk appraisal, and risky behavior. Personality and Individual Differences 14: 41-52.

56. Schutte NS, Malouff JM, Haggerty LE, Cooper DJ, Golden JT, et al. (1998) Development and Validation of a Measure of Emotional Intelligence. Personality and Individual Differences 25: 167-177.

57. Chan DW (2003) Hardiness and its role in the stress-burnout relationship among prospective Chinese teachers in Hong Kong. Teaching and Teacher Education 19: 381-395.

58. Hobfoll SE (2001) The influence of culture, community and the nestedself in the stress process: Advancing conservation of resources theory. Applied Psychology: An International Review 50: 337-421.

59. Paul T (1995) Development and validation of a short hardiness measure. American Pyschological Society. Washington DC.

60. Bhattacharya S, Basu J (2007) Distress, wellness and organizational role stress among IT professionals: Role of life events and coping resources. Journal of the Indian Academy of Applied Psychology. 33: 169-178.

61. Wood PB, Cochran JK, Pfefferbaum B, Arneklev BJ (1995) Sensation Seeking and Delinquent Substance Abuse: An Extension of Learning Theory. Journal of Drug Issues 25: 173-193. 